\title{
Development of a Disposable Pipette Extraction Method Using Coffee Silverskin as an Adsorbent for Chromium Determination in Wastewater Samples by Solid Phase Extraction
}

\author{
Weida R. Silva, ${ }^{\oplus a}$ Bruno E. S. Costa, ${ }^{\oplus a}$ Alex D. Batista, ${ }^{\oplus a}$ Vanessa $N$. Alves ${ }^{\circledR * b}$ and \\ Nivia M. M. Coelho ${ }^{\circledR a}$ \\ anstituto de Química, Universidade de Uberlândia, Av. João Naves de Ávila 2121, \\ 38400-902 Uberlândia-MG, Brazil \\ ${ }^{b}$ Departamento de Química, Universidade de Goiás, Av. Dr. Lamartine Pinto de Avelar, 1120, \\ Setor Universitário, 75704-020 Catalão-GO, Brazil
}

\begin{abstract}
A procedure using disposable pipette tips adapted for solid-phase extraction, known as DPX-SPE, was used as an alternative way for the chromium determination in wastewater samples. DPX-SPE consists of a device which allows a dynamic contact between the sample and the solidphase. A residue obtained from the processing of coffee beans, denominate coffee silverskin, was used as a new adsorbent. Characterization techniques revealed properties of lignocellulosic materials with potential application for chromium adsorption. The parameters including adsorbent mass $(25.00 \mathrm{mg})$, elution solvent $\left(0.1 \mathrm{~mol} \mathrm{~L}^{-1} \mathrm{HCl}, 200 \mu \mathrm{L}\right)$ and $\mathrm{pH}(2.0)$ were optimized. Thus, $1.00 \mathrm{~mL}$ of deionized water for conditioning, $4.00 \mathrm{~mL}$ of sample, 2 extraction cycles and 1 elution cycle were the employed conditions. Enrichment factor of 12, limit of detection of $6.00 \mu \mathrm{g} \mathrm{L}^{-1}$ and relative standard deviation (RSD) $1.3 \%(\mathrm{n}=3)$ were obtained. The method proved to be fast, cheap, environmentally friendly, and simple, providing good recoveries (104-113\%), and it was satisfactorily applied in real samples.
\end{abstract}

Keywords: chromium, coffee silverskin, DPX, FAAS, SPE, wastewater

\section{Introduction}

Chromium is the sixth most abundant element in the earth's crust, found in natural deposits as ores containing other elements, where it is found in small quantities associated with other metals, particularly with iron as chromite $\left(\mathrm{FeCr}_{2} \mathrm{O}_{4}\right)$ and with lead as crocoite $\left.\left(\mathrm{PbCrO}_{4}\right)\right)^{1-3}$ It is present in the ecosystem as a result of the weathering of the earth's crust and deposition of waste from anthropogenic activities. It is an important industrial metal used in alloys such as stainless steel, protective coatings, pigments for paints, cement, paper, rubber, and among another applications..$^{4-6}$

Chromium can be found in natural waters in two stable oxidation states, $\mathrm{Cr}^{\mathrm{III}}$ and $\mathrm{Cr}^{\mathrm{VI}}$, which present different toxicity. $\mathrm{Cr}^{\mathrm{III}}$ is an essential nutrient, while the hexavalent form, $\mathrm{Cr}^{\mathrm{VI}}$, is listed as a known human carcinogen. The presence and ratio between these two forms depend on

*e-mail: vanessanalves@ gmail.com

Editors handled this article: Eduardo Carasek and Maria das Graças A. Korn (Associate) several processes, including chemical and photochemical redox transformation, precipitation/dissolution, and adsorption/desorption reactions. ${ }^{1}$

A Brazilian governmental agency responsible for the regulation of contaminants in waters, the National Council of Environment (CONAMA) in resolution number 430/2011, established that the maximum permissible concentration in wastewater is $0.1 \mathrm{mg} \mathrm{L}^{-1}$ for $\mathrm{Cr}^{\mathrm{VI}}$ and $1.0 \mathrm{mg} \mathrm{L}^{-1}$ for $\mathrm{Cr}^{\mathrm{III}}$. To ensure that wastewater meets environmental resolutions for disposal in bodies of water, it is necessary to monitor the concentration of contaminating metals. In this scenario, it is important to develop analytical methods that allow the monitoring of chromium and its $\mathrm{Cr}^{\mathrm{III}}$ and $\mathrm{Cr}^{\mathrm{VI}}$ species, that can be harmful even at low concentrations.

For that matter, several analytical methodologies have been developed for extraction, preconcentration and speciation ${ }^{8}$ of chromium in waters, including coprecipitation, ${ }^{9}$ liquid-liquid extraction, ${ }^{10}$ dispersive liquid-liquid microextraction, ${ }^{11-13}$ cloud point extraction, ${ }^{14}$ and solid-phase extraction. ${ }^{15,16}$ The solid-phase extraction (SPE) is a well-known and established technique for 
extraction and preconcentration of analytical species. ${ }^{17,18}$ It is an ideal technique to concentrate analytes of a liquid matrix, at a trace level, uses a small amount of solvent, and presents good recovery with high enrichment factors. Great attempts have been made to develop new selective and sensitive analytical techniques capable of extracting and/or isolating specific analytes in the most varied matrices. ${ }^{19,20}$

A variation of the traditional SPE is the extraction using a disposable pipette tip (DPX: disposable pipette extraction). ${ }^{19}$ DPX allows rapid extraction of samples and solutions using disposable tips, instead of cartridges or test tubes. ${ }^{21}$ The DPX technique consists of the modification of a pipette tip (1.0 or $5.0 \mathrm{~mL}$ ), where a small amount of sorbent is contained therein between two filters. In DPX, samples are mixed with the dispersed sorbent to provide rapid equilibrium by the effective contact between them. ${ }^{19,22}$ The technique has been applied mainly in the determination of food contaminants, drugs, and few publications devoted to metal analytes. ${ }^{23}$ However, there are still few studies using DPX for extraction and preconcentration of metallic ions.

Despite the description of the device as disposable tips, the pipette tips can be reused, and the commercial solid phase can be replaced according to interest, which allows the use of alternative materials, so natural adsorbents are a viable and interesting alternative for use in conjunction with DPX. ${ }^{19,24}$ Thus, the development of new adsorbents with high potential adsorptive, better selectivity or specificity for the target analytes, greater sorption ability, and chemical improvement or physical-mechanical stability is of great interest. ${ }^{25}$ The low-cost natural adsorbent is one of the promising areas of research applied in analytical procedures in the determination of metals in water samples. ${ }^{26}$

These procedures may also be satisfactorily required in the remeasurement of chromium in aqueous systems, including a solid phase functionalization. ${ }^{27}$ The exploration of new materials from this class of adsorbents should be increasingly encouraged to promote sustainability in all stages of the procedure. The residues generated during the processing of coffee beans are examples to be used in this proposal.

Coffee is one of the most frequently consumed drinks in the world. According to the International Coffee Organization, ${ }^{28}$ world coffee exports totaled 10.07 million bags in September 2021, compared to 10.59 million bags in September 2020. The coffee bean for consumption goes through industrial processing, which can happen through different processing routes: dry, wet way or semi-wet way. ${ }^{28}$ There are several solid residues generated during different processes. Coffee silverskin is the only by-product produced during the coffee beans roasting process. ${ }^{29}$ These residues can be a source of raw material for the food, pharmaceutical, and cosmetic industry, in addition to being frequently used to generate energy in boilers for mechanical dryers and as fertilizers. ${ }^{28,30}$ The coffee silverskin residue is mainly used as fertilizer or fuel, however, studies show that it would be of great use to improve the fiber content in foods and as an antioxidant potential. ${ }^{31-33}$ The present study will investigate the potential of the coffee silverskin as an adsorbent material.

Thus, this article aimed the use of coffee silverskin as a solid phase in disposable tips (DPX), to the development of a procedure for extraction and preconcentration of chromium in wastewater and detection by flame atomic absorption spectrometry (FAAS). The presented method stands out for showing an alternative solid phase with low cost, an advantageous short extraction time for application in sample preparation.

\section{Experimental}

\section{Chemicals, reagents, and sample}

All solutions were prepared with ultra-pure deionized water (resistivity of $18.2 \mathrm{M} \Omega \mathrm{cm}$ ) obtained from a purification system (Gehaka, São Paulo, Brazil). Chromium standard solutions with concentrations ranging from 1.0 to $100.0 \mathrm{mg} \mathrm{L}^{-1}$ were prepared by successive dilutions of stock solution $1000.0 \mathrm{mg} \mathrm{L}^{-1}$ (SpecSol Chimlab, Jacareí, Brazil). All plastic vials and used glassware were decontaminated in a $10 \% \mathrm{v} / \mathrm{v} \mathrm{HNO}_{3}$ bath for $10 \mathrm{~h}$, followed by rinsing with deionized water and allowed to dry at room temperature.

In the study of interfering metals, solutions of $\mathrm{Ca}, \mathrm{Fe}$, $\mathrm{Sr}, \mathrm{Ba}$ and $\mathrm{Mg}$ were prepared from $1000.0 \mathrm{mg} \mathrm{L}^{-1}$ standard (Carlo Elba, Val de Reuil, France). For each standard chromium solution, known amounts of the interferent to be studied were added in the following proportions in relation to the chromium concentration 1:0.5 and 1:1. To elution, solutions were all prepared at $0.5 \mathrm{~mol} \mathrm{~L}^{-1}$ from reagents of analytical grade: $\mathrm{HCl}$ (Dinâmica, São Paulo, Brazil), $\mathrm{NaOH}$ (Synth, São Paulo, Brazil), and $\mathrm{HNO}_{3}$ (Vetec, Duque de Caxias, Brazil).

The water samples were collected at two points in the region of the city of Caldas Novas, Goiás, Brazil. The water (sample 1) represents treated water for supply. The wastewater (sample 2) was collected at one point after the discharge of treated effluent by a conventional effluent treatment plant. The samples were not submitted to any preparation stage. They were only filtered with the aid of syringe filter with polyether sulfone membrane (PES) $0.45 \mu \mathrm{m}, 30 \mathrm{~mm}$ (Chromastore, São Paulo, Brazil) to remove solid suspensions and stored under refrigeration $\left(4{ }^{\circ} \mathrm{C}\right)$ in decontaminated plastic bottles. 
Instrumentation

The determination of chromium in the aqueous solutions before and after extraction in DPX using the adsorbent material was performed using a SpectrAA-220 (Varian, Victoria, Australia) flame atomic absorption spectrometer (FAAS). As a radiation source, a hollow cathode lamp (Agilent Technologies, Australia) operated at a specific wavelength line of $425.4 \mathrm{~nm}$, current of $7 \mathrm{~mA}$ and spectral slot width of $0.1 \mathrm{~nm}$. The acetylene (White Martins, São Paulo, Brazil) and air flow rates, as well as the burner height, were adjusted to obtain a maximum absorbance signal under the operating conditions, the parameters followed the manufacturer's recommendations, airflow $300 \mathrm{~mL} \mathrm{~min}{ }^{-1}$, and signal integration time $5.0 \mathrm{~s}$.

Potentiometric $\mathrm{pH}$ measurements were made with a $\mathrm{pH}$ meter equipped with a combined glass electrode and $\mathrm{Ag} / \mathrm{AgCl}$ as the reference electrode, model PG1800 (Gehaka, São Paulo, Brazil).

\section{Adsorbent material}

The coffee silverskin obtained from the coffee bean processing industry has varied granulometry. For standardization of the size of the particles, the solid was passed through sieves with a standard opening of 180 , 150 , and $90 \mu \mathrm{m}$, which were manually agitated. Most of the adsorbent material was retained in the $150 \mu \mathrm{m}$ sieve, which is then the size adopted for the other characterization and adsorption studies.

An initial study of the adsorption of $\mathrm{Cr}$ for structural characterization of the coffee silverskin proceeded in batch. The untreated sorbent material (in natura) was placed in contact with the metallic ion solution to evaluate the adsorbent properties. For this, $15.0 \mathrm{~mL}$ of chromium solution with a concentration of $1.0 \mathrm{mg} \mathrm{L}^{-1}$ was left in contact with the mass of adsorbent material ranging from 25.0 to $200 \mathrm{mg}$. The mixtures were kept on a stirring table for an interval of 1 to $50 \mathrm{~min}$. Afterward, each mixture was filtered in a vacuum filtration system, supported on qualitative filter paper (Whatman, Grade 1, $460 \mathrm{~mm} \times 570 \mathrm{~mm}$ ). To evaluate the adsorption efficiency in these preliminary tests the supernatants were analyzed by FAAS. More information about the results obtained with the batch assays are presented in the Supplementary Information (SI) section (Figures S1 and S2).

\section{Characterization of adsorbent}

To determine the zero-load point $\left(\mathrm{pH}_{\mathrm{PCZ}}\right)$, suspensions were prepared with $25.0 \mathrm{~mL}$ of deionized water with a previously adjusted $\mathrm{pH}$ (initial $\mathrm{pH}$ ) and $200.0 \mathrm{mg}$ of the adsorbent. $\mathrm{pH}$ adjustments were performed by adding solutions of $\mathrm{HCl}$ or $\mathrm{NaOH} 0.10 \mathrm{~mol} \mathrm{~L}^{-1}$ to obtain initial $\mathrm{pH}$ values of $1,2,3,4,5,6,7,8,9,10,11$, and 12 . The suspensions were placed in a closed bottle, manually shaken, and remained at rest for $24 \mathrm{~h} .{ }^{34}$ Then the mixtures were filtered, and the $\mathrm{pH}$ of the supernatant was measured, determining the final $\mathrm{pH}$.

The vibrational spectra in the infrared region with Fourier transform (FTIR) were obtained using a PerkinElmer FTIR Frontier Single Range spectrophotometer (Waltham, USA), in the region between 4000 and $500 \mathrm{~cm}^{-1}$. The sample analysis was made in the solid-state, using the attenuated total reflectance (ATR) accessory with the diamond crystal.

The coffee silverskin micrographs from scanning electron microscopy (SEM), were obtained using a scanning electron microscope, model VEGA3 Tescan (Brno, Czech Republic), equipped with an X-ray dispersive energy spectroscopy detector (XR-EDS). Before the analysis, the samples were covered with gold, applying an acceleration voltage of $5.0 \mathrm{kV}$ and the chosen magnifications were $100 \times$, $1000 \times, 5000 \times$ and $10000 \times$.

Thermogravimetric analysis (TGA) was performed using thermogravimetric analyzer, TGA with DTG detector-60H, series C30574500199TK, Shimadzu (Kyoto, Japan). The TGA curve was obtained in the temperature range from 25 to $600{ }^{\circ} \mathrm{C}$, at a heating rate of $20^{\circ} \mathrm{C} \mathrm{min}-1$ under an inert nitrogen atmosphere with flow $50 \mathrm{~mL} \mathrm{~min}^{-1}$.

\section{Solid-phase extraction with a disposable pipette (DPX)}

The DPX tips were prepared before each experiment using $25.0 \mathrm{mg}$ of the coffee silverskin as the solid phase. The main extraction parameters were optimized by a univariate study to establish the best adsorption equilibrium condition. During the optimization studies, chromium standard solution with concentration $1.0 \mathrm{mg} \mathrm{L}^{-1}$ was used. This concentration was chosen according to the result of variation of the $\mathrm{Cr}$ concentration in the range of 0.5 to $10.0 \mathrm{mg} \mathrm{L}^{-1}$, presented in Figure S3 in the SI section. The Cr solution or sample was aspirated into the tip of the nozzle and the air was then mixed with the adsorbent to form a suspension. After $30 \mathrm{~s}$ the solution was dispensed and this process was considered a cycle. ${ }^{35,36}$ The number of cycles to quantitatively remove chromium was evaluated from 2 to 6 cycles and adsorbent mass from 5.0 to $25.0 \mathrm{mg}$. The influence of the $\mathrm{pH}$ on the extraction efficiency was

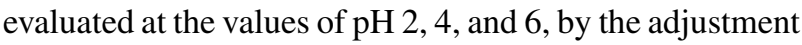
with $0.10 \mathrm{~mol} \mathrm{~L}^{-1} \mathrm{HCl}$ or $\mathrm{NaOH}$ solutions. ${ }^{28}$ For the chromium elution, $\mathrm{HCl}, \mathrm{HNO}_{3}$ and $\mathrm{NaOH}$ were evaluated as elution solvents, at different concentrations and volumes. 
The solvent was sucked into the nozzle, followed by aspiration of air, initially in a single cycle. The number of elution cycles was subsequently checked. ${ }^{35,36}$

\section{Results and Discussion}

\section{Characterization of the adsorbent coffee silverskin}

The main functional groups present in the coffee silverskin in natura were characterized by FTIR analysis. The profile of the spectrum is characteristic of lignocellulosic materials and the amount of absorption bands indicates the complex nature of the adsorbent solid, as presented in Figure 1.

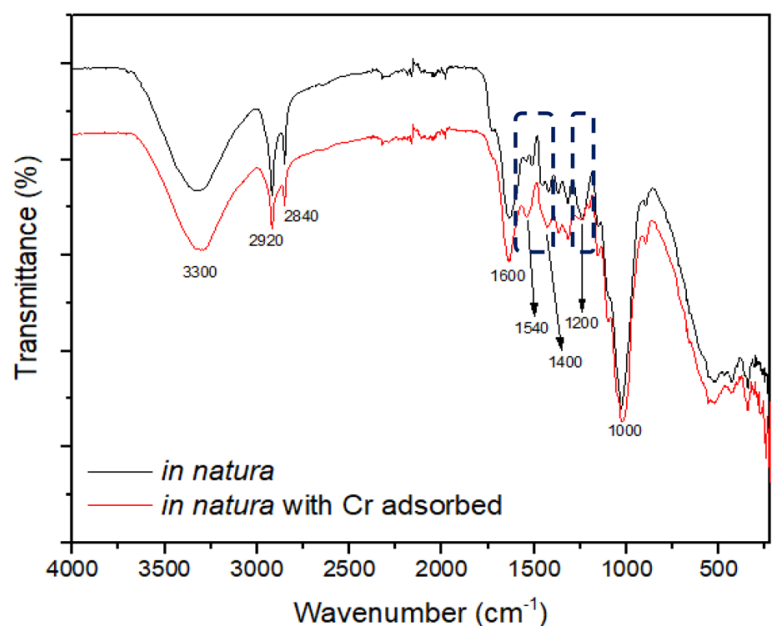

Figure 1. FTIR-ATR spectrum of coffee silverskin in natura.

The chemical composition of the adsorbent surface influences the adsorption capacity of metals, thus helping to understand the possible interactions between the adsorbent and the analyte. ${ }^{37-39}$ The broadband centered at $3330 \mathrm{~cm}^{-1}$ is attributed to the stretching of the $\mathrm{O}-\mathrm{H}$ bond in the protein, fatty acids, carbohydrates, and lignin units. Additionally, due to the protein content present in the coffee silverskin, there is still a contribution due to $\mathrm{N}-\mathrm{H}$ stretching in the bondage of amides in this region. ${ }^{32}$

The peaks that appear in 2920 and $2840 \mathrm{~cm}^{-1}$ correspond respectively to the asymmetric and symmetric stretching of the $\mathrm{C}-\mathrm{H}$ bond in the $\mathrm{CH}_{2}$ group, which indicates long chains of alkanes, the basis for the structure of proteins and fibers that are present in plant material. ${ }^{32}$ The broadband centered on $1600 \mathrm{~cm}^{-1}$ is an approximate attribution for stretching of carbonyl groups from fatty acid esters and peptide bond of proteins. Bands at 1400 and $1460 \mathrm{~cm}^{-1}$ indicate the aromatic $\mathrm{C}-\mathrm{C}$ stretching with $\mathrm{C}-\mathrm{H}$ deformations. The $\mathrm{C}-\mathrm{O}$ stretch, at $1200 \mathrm{~cm}^{-1}$ is related to lignin content, due to phenolic and ether in guaiacyl units and bands close to $1300 \mathrm{~cm}^{-1}$ are corresponding to the $\mathrm{C}-\mathrm{O}$ stretching of the syringe structure. ${ }^{40}$ The band at $1000 \mathrm{~cm}^{-1}$ indicates the stretching of $\mathrm{C}-\mathrm{O}$, a bond present in alcohol, common in polysaccharides that are part of the composition of plant material. ${ }^{41}$

The overlapping of the FTIR spectra of the adsorbent in natura and containing $\mathrm{Cr}$ adsorbed does not show, in principle, changes resulting from specific interactions with the metal ion, which generally occur in wavenumbers below $500 \mathrm{~cm}^{-1}$. However, when the set of bands between 1600 and $1200 \mathrm{~cm}^{-1}$ is compared more carefully, it is possible to notice some subtle changes indicative of the desired adsorption: after adsorption with $\mathrm{Cr}$, there is a better definition of the band at $1540 \mathrm{~cm}^{-1}$. This band may be related to the electronic reallocation of the peptide bond to favor the group $-\mathrm{C}=\mathrm{NH}^{+}$. This idea can be confirmed by the disappearance of a small band at $1500 \mathrm{~cm}^{-1}$, attributed to the $\mathrm{N}-\mathrm{H}$ bond of the secondary amides. Confirmation of this positively charged group contributes to retaining the analyte through non-specific interactions involving the formation of a double electrical layer.

In the in natura sorbent, shoulders located at 1750 and $1476 \mathrm{~cm}^{-1}$ reveal a small portion of carboxylic acid groups, characteristic of the symmetrical elongation of the axial deformation of the deprotonated carboxyl groups. ${ }^{42}$ These shoulders do not appear after adsorption with $\mathrm{Cr}$, suggesting that the electrostatic interactions of a small negatively charged portion in the charge balance of the adsorbent are also responsible for the small adsorption. In this sense, there is also a more pronounced disappearance of the band at $1200 \mathrm{~cm}^{-1}$, indicating the interference of the metal ion in the phenolic structure of the guaiacyl groups of lignin. ${ }^{40-43}$

In addition to investigating the functional groups of the material adsorbent surface, it is necessary to evaluate its morphology. A coffee silverskin has a very heterogeneous surface, regions with needle-shaped blocks, and small particle size, as shown in Figure 2. With the increase in magnification, amorphous structures made up of stretched grooves are observed that can contribute to the diffusion of metal ions on the material surface. Porous, irregular, and interstice regions, that facilitate the process of adsorption of metal ions, are also observed in the images.

The micrographs obtained for the material after the batch adsorption process (Figures 2e and 2f) show a morphological change through the disappearance of the previously observed grooves. This time, the filling of the deformations is noticeable, making the surface more uniform.

Also analyzing the material surface, an estimate of the constituent chemical elements was obtained using the X-ray fluorescence spectra with dispersive energy (XR-EDS). This spectra of the in natura material and after chromium adsorption are shown in Figure S4 of the SI section. The 


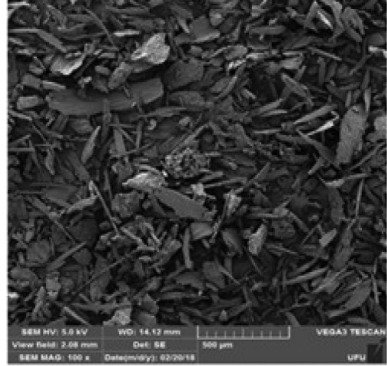

(a)

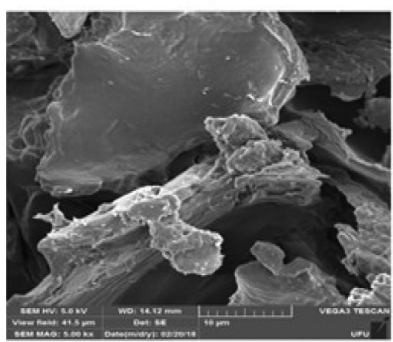

(c)

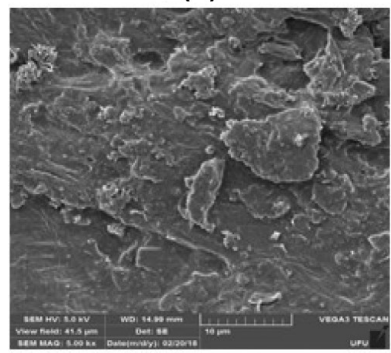

(e)

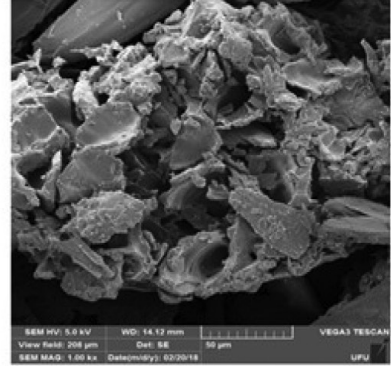

(b)

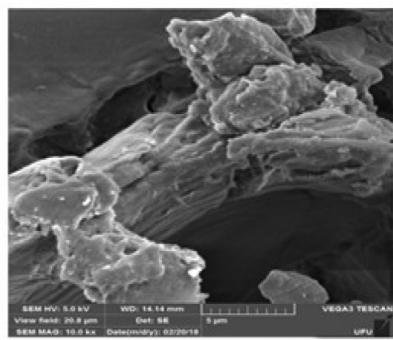

(d)

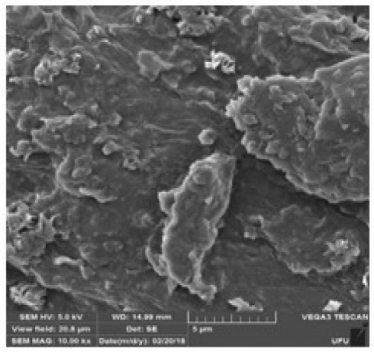

(f)
Figure 2. Images obtained in SEM of the coffee silverskin. Magnifications: (a) $100 \times$ (b) $1000 \times$ (c) $5000 \times$ (d) $10000 \times$ (e) adsorption process $5000 \times$ (f) adsorption process $10000 \times$.

apparent concentration profile of the mapped regions of the adsorbent reveals that the elements $\mathrm{C}, \mathrm{O}, \mathrm{K}$, and $\mathrm{Ca}$ are the majority, varying in that order between 56.5 to $2.82 \%$ of the composition. These elements are associated with carbohydrates, fibers, and mineral nutrients. When comparing with the XR-EDS spectrum obtained from the material after adsorption, it is not possible to directly identify the presence of $\mathrm{Cr}$, due to the limitations of low detectability of the equipment $(1.0 \% \mathrm{~m} / \mathrm{m})$ under the same experimental conditions. However, it is interesting to note that there is a significant decrease in the alkali metals $\mathrm{K}$ and $\mathrm{Ca}$, after adsorption with $\mathrm{Cr}$. These elements have high mobility, and probably could easily be solubilized in the extension of the double electric layer, to accommodate more polarizable metallic elements, as in the case of $\mathrm{Cr}$, which is also susceptible to more efficient coordination with the active sites of the material.

Thermogravimetric analysis (TGA) and derivative thermogravimetry (DTG) were performed to complement information about the structural constitution of the adsorbent. The results confirm the characteristic composition of the class of lignocellulosic adsorbents verified with FTIR. The thermogram and its derivative are shown in Figure S5 of the SI section. The thermal decomposition of coffee silverskin basically occurred in three stages: the first represents the loss of mass by $10 \%$ due to the elimination of adsorbed water $\left(0\right.$ to $\left.250{ }^{\circ} \mathrm{C}\right)$. As the coffee silverskin is a residue obtained from the industrial roasting, the material moisture is small. The second stage corresponds to $40 \%$ of the mass variation occurring from 250 to $350^{\circ} \mathrm{C}$. In this temperature range occurs the decomposition of organic matter that make up the protein fraction and fibers present in the plant material. Finally, the third stage involving the temperature range from 350 to $550{ }^{\circ} \mathrm{C}$ signals the decomposition of other components such as: cellulosic and lignin units. ${ }^{42,44}$

The evaluation of the zero-load point shows a practically constant range between $\mathrm{pH} 6$ and 9, as presented in Figure 3. In this range, there is a zero-charge point, where the total surface charge is zero. The $\mathrm{pH}_{\mathrm{PCZ}}$ is defined as the intersection point on the $\mathrm{x}$ axis in Figure 3, thereby the $\mathrm{pH}_{\mathrm{PCZ}}$ of the coffee silverskin was defined at $\mathrm{pH} 6 .{ }^{45}$

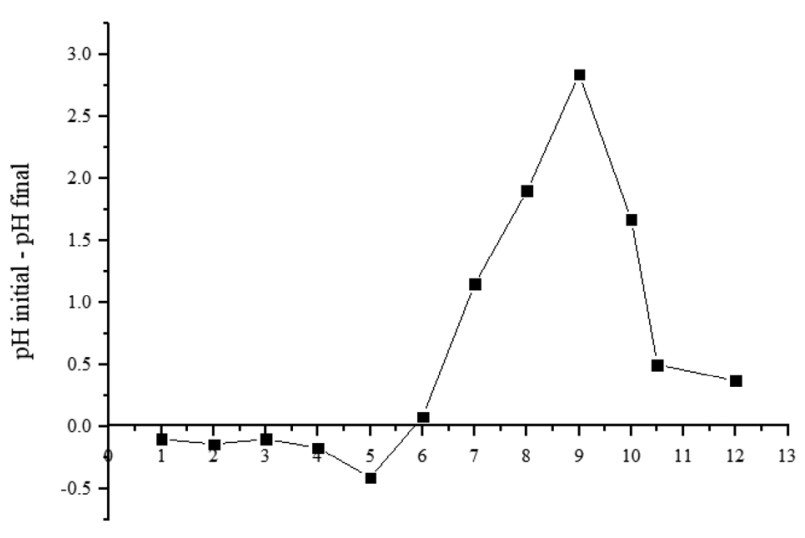

$\mathrm{pH}$ initial

Figure 3. Evaluation of the points of zero charge (PZC) of the coffee silverskin.

In a medium with a $\mathrm{pH}$ greater than 6 , the coffee film is negatively charged, having the ability to adsorb positively charged species. In a medium with a $\mathrm{pH}$ under 5 , the plant material is positively charged and can adsorb negative species.

The characteristics presented by the in natura coffee film highlight the promising properties to be explored in metal ion adsorption processes since it has a composition common to other alternative materials investigated for this purpose. Additionally, it is cheaper, as it is an industrial residue and easily obtained. ${ }^{46}$

\section{Optimization of DPX steps}

The influence of the $\mathrm{pH}$ on the chromium adsorption 
can be evaluated by the extent of protonation/deprotonation equilibrium of acidic functional groups. The $\mathrm{pH}$ adjustment was made with $0.10 \mathrm{~mol} \mathrm{~L}^{-1} \mathrm{HCl}$ or $\mathrm{NaOH}$ solutions. Buffer solutions could interfere with the chromium adsorption process, due to the competition of the metal ions with the ions present in the buffer for the adsorption sites. In addition to the possibility of complexation of the buffer anions with the analyte. ${ }^{45}$ The choice of evaluated $\mathrm{pH}$ values is considered a range that prevents the removal of chromium by precipitation. $\mathrm{pH}$ values of 2,4 and 6 resulted in $72.0 \pm 0.9,67.0 \pm 1.6$, and $22.1 \pm 0.8 \%$ of chromium adsorption, respectively. The most significant extraction occurred at $\mathrm{pH} 2$. The $\mathrm{pH}_{\mathrm{PCZ}}$ values in the range 6 to 9 , indicate amphoteric surfaces, in general, acidic and basic groups of the material surface are affected equally by the $\mathrm{pH}$ of the medium, which may contribute to the adsorption of $\mathrm{Cr}$ in this condition.

At this $\mathrm{pH}, \mathrm{Cr}^{\mathrm{III}}$ manifests predominantly as a positively charged solvated ion. Note that at first, adsorption is not described by forces of direct electrostatic attraction between the metal ion and the adsorbent. However, it is reasonable to formulate the hypothesis that at $\mathrm{pH} 2.72$ there is an influence of the double electrical layer established on the material surface with the analyte. Under conditions of ionic strength of the medium, the $\mathrm{Cr}$ ions can manifest itself as a cluster surrounding a negative ionic atmosphere that diffuses over the water film that makes up the double electrical layer, in a dipole orientation that favors the forces of electrostatic interactions. ${ }^{47-49}$ For $\mathrm{Cr}^{\mathrm{VI}}$ this does not represent a problem since the species manifested negatively charged as $\mathrm{HCrO}_{4}^{-}$in this $\mathrm{pH}$ range. ${ }^{44}$

The results point out a non-specific adsorption process of $\mathrm{Cr}$ concerning the heterogeneous nature of the material. Several studies ${ }^{47-49}$ demonstrate that the interactions of metal ions involving adsorbents of lignocellulosic composition cannot be described only by a single mechanism, but through physical and chemical processes that occur simultaneously interactions. Such processes receive a significant contribution from forces related to chemical interactions as a limiting step of adsorption. ${ }^{50}$

For the use of this DPX extraction, each step must be optimized to establish the best equilibrium condition. The conditioning cycle consists of the aspiration and dispensing of $1.0 \mathrm{~mL}$ of deionized water, this step serves to compact the solid phase in the tip, as the silver film when transferred is dispersed inside tip. ${ }^{24}$ The dispensed water is taken for reading in the FAAS, this being the analytical blank signal for reference to the obtained supernatants. The tip used in DPX holds up to $5.0 \mathrm{~mL}$ of liquid, which allows aspiration of different sample volumes. The evaluated volumes considered that inside the tip, in addition to the solution, space is necessary so that in the air aspiration stage, the sample and the solid phase are well mixed. The volume of solution aspirated for the extraction of $\mathrm{Cr}$ influences the analyte dosage available for adsorption. Therefore, a volume of $4.0 \mathrm{~mL}$ was chosen.

To evaluate the influence of solid-phase mass, a study was performed with $5.0,10.0,20.0$, and $25.0 \mathrm{mg}$ of adsorbent. Considering the volume of the sample already defined, the best mass of coffee films to be used was set at $25.0 \mathrm{mg}$ (Figure S6, SI section), which holds a greater number of local assets and, therefore, greater metal ion adsorption. This condition still allows an adequate volume of air in the internal capacity of the device that which provided a more efficient dispersion.

The number of extraction cycles is an important parameter, as it can increase the amount of adsorbed chromium in the solid phase, however it also influences the extraction time, as each cycle takes $30 \mathrm{~s} .^{25,36,38}$ The variation in the number of extraction cycles was evaluated as percentage of adsorption, according to equation 1 , where $\mathrm{C}_{0}$ is the initial concentration of chromium $\left(\mathrm{mg} \mathrm{L}^{-1}\right)$ and $\mathrm{C}_{\mathrm{e}}$ is the metal concentration in equilibrium $\left(\mathrm{mg} \mathrm{L}^{-1}\right)$, after $30 \mathrm{~s}$.

$\operatorname{Adsorption}(\%)=\frac{\mathrm{C}_{0}-\mathrm{C}_{\mathrm{e}}}{\mathrm{C}_{0}} \times 100$

As presented in Figure 4, there is no significant differences in the values obtained for more than 2 extraction cycles. Considering the total extraction time, 2 cycles become enough for a good removal of the analyte. A higher number of extraction cycles is unnecessary because as the same solution is repeatedly aspirated, the active sites are being filled and with the equilibrium reached it is not possible to increase the removal of $\mathrm{Cr}^{25}$

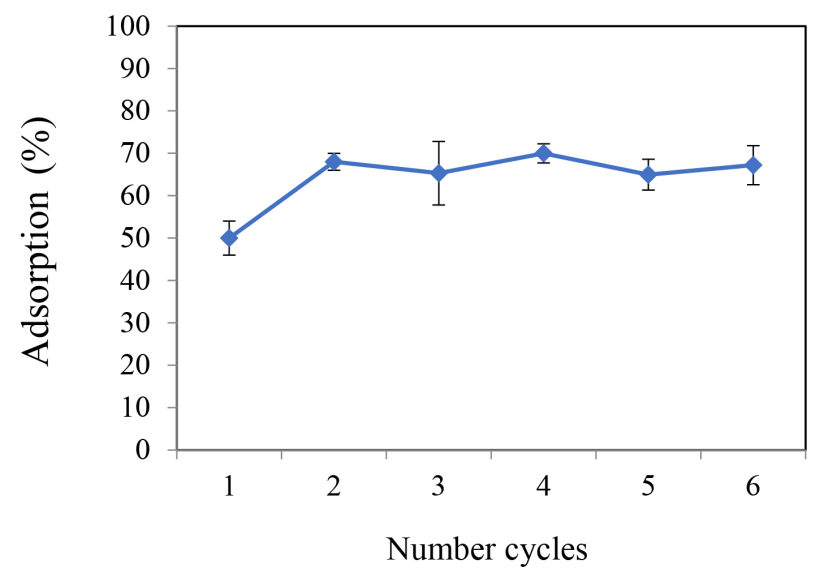

Figure 4. Study of the number of solution extraction cycles. Conditions: $25.0 \mathrm{mg}$ of adsorbent in natura; $1.0 \mathrm{mg} \mathrm{L}^{-1} \mathrm{Cr}$ solution; 1 conditioning cycle $(1.0 \mathrm{~mL})$; sample aspiration $(4.0 \mathrm{~mL})$. 
For desorption of $\mathrm{Cr}$ from the adsorbent surface, $1 \mathrm{~mL}$ of $0.5 \mathrm{~mol} \mathrm{~L}-1 \mathrm{HCl}, \mathrm{NaOH}$, and $\mathrm{HNO}_{3}$ solutions were evaluated, and the results are shown in Figure 5. The best analytical signal in the elution was observed only for the hydrochloric acid, which is therefore the best eluent to be used due to the negative charge on chloride ions. In these conditions, chloride anions have greater affinity with the solid phase than chromium, thus facilitating their exit from the surface of the adsorbent material. A decrease in the signal is observed using $\mathrm{HNO}_{3}$, which may be related to probable oxidation to $\mathrm{Cr}^{\mathrm{VI}}$ and thus favor its adsorption by electrostatic interaction. Using $\mathrm{NaOH}$ as an eluent, the lowest signal for $\mathrm{Cr}$ desorption was observed in relation to $\mathrm{HCl}$ and $\mathrm{HNO}_{3}$. In alkaline solvent, $\mathrm{Cr}$ III can form poorly soluble hydroxides, decreasing the extraction efficiency.

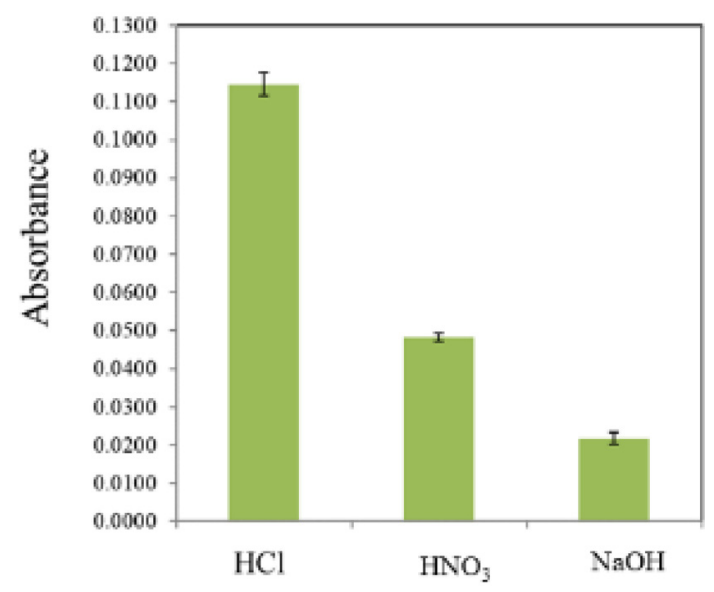

Eluents

Figure 5. Initial study of the elution step. Conditions: $25.0 \mathrm{mg}$ of adsorbent in natura; $1.0 \mathrm{mg} \mathrm{L}^{-1} \mathrm{Cr}$ solution with $\mathrm{pH} 2.0 ; 1$ conditioning cycle $(1.0 \mathrm{~mL}) ; 2$ sample aspiration cycles $(4.0 \mathrm{~mL}) ; 1$ elution cycle $(1.0 \mathrm{~mL})$.

As previously mentioned, when choosing the eluent, aggressions to the environment are considered, so diluted acids must be used. Figure 6 shows the results of elution for different concentrations of hydrochloric acid as a function of the analytical signal. Diluted $\mathrm{HCl}$ solutions ( 0.05 and $0.1 \mathrm{~mol} \mathrm{~L}^{-1}$ ) showed the best elution efficiency. Thus, the $0.1 \mathrm{~mol} \mathrm{~L}^{-1}$ concentration was chosen as the best condition for eluting chromium. Since it managed to desorb a larger amount of the metal ion.

The preconcentration factor can be improved by decreasing the eluent volume. To achieve the best extraction efficiency with maximum preconcentration effect, the influence of the eluent volume was evaluated, as presented in Figure 7. The smaller evaluated volume $(0.2 \mathrm{~mL})$ provided an increase in the analytical signal of approximately 5 times compared to $1.0 \mathrm{~mL}$, and it was selected as the optimum volume. However, this volume permits only 1 elution cycle

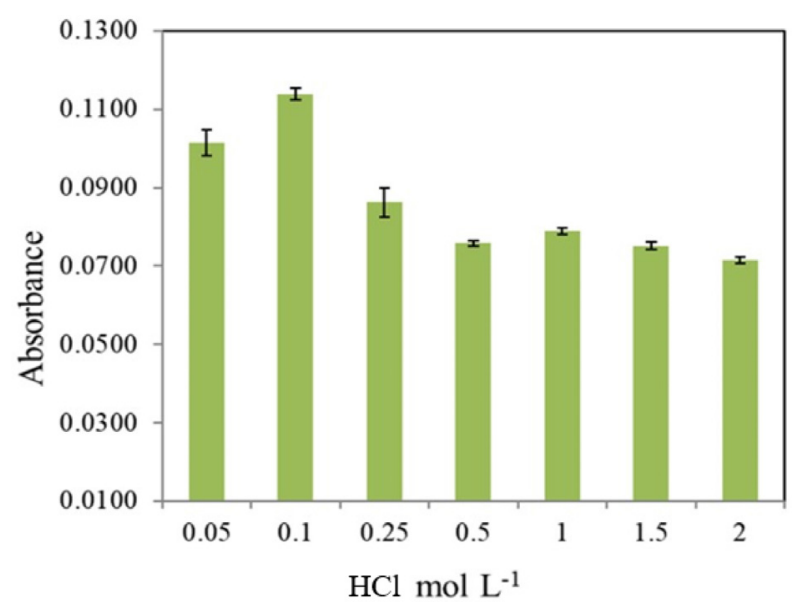

Figure 6. Effect of the eluent concentration on chromium elution. Conditions: $25.0 \mathrm{mg}$ of adsorbent in natura, solution $1.0 \mathrm{mg} \mathrm{L}^{-1} \mathrm{Cr}$ with $\mathrm{pH} 2.0 ; 1$ conditioning cycle $(1.0 \mathrm{~mL}) ; 2$ sample aspiration cycles $(4.0 \mathrm{~mL}) ; 1$ elution cycle $(1.0 \mathrm{~mL})$.

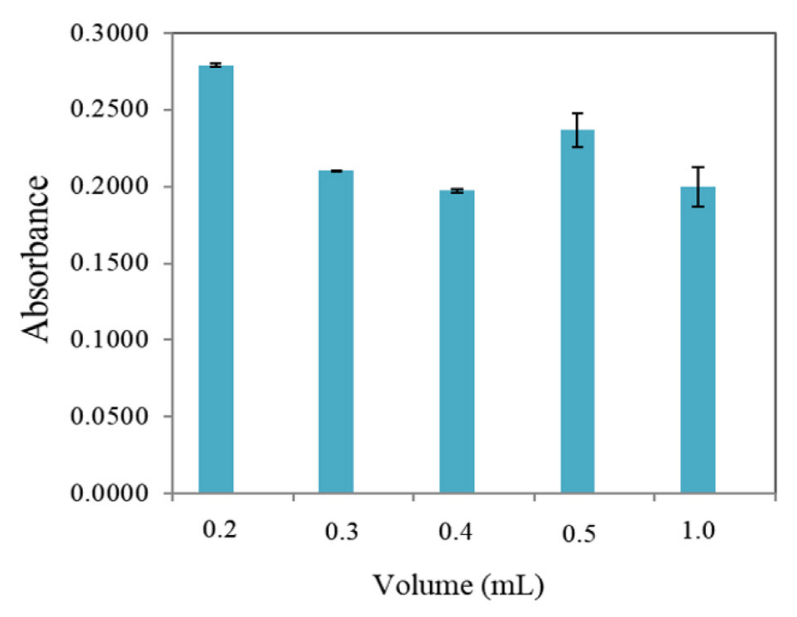

Figure 7. Influence of the eluent volume. Conditions: $25.0 \mathrm{mg}$ of adsorbent in natura, solution $1.0 \mathrm{mg} \mathrm{L}^{-1} \mathrm{Cr} \mathrm{pH}=2 ; 1$ conditioning cycle $(1.0 \mathrm{~mL}) ; 2$ sample aspiration cycles $(4.0 \mathrm{~mL}) ; 1$ elution cycle with different volumes.

with effective contact between adsorbent and eluent. The optimized conditions are shown in Table 1.

Table 1. Optimized conditions for Cr extraction

\begin{tabular}{lc}
\hline Variable studied & Result \\
\hline Volume conditioning / mL & 1.0 \\
Sample volume / mL & 4.0 \\
Mass of adsorbent / mg & 25.0 \\
Extraction cycles & 2 \\
Eluent / (mol L ${ }^{-1}$ ) & $\mathrm{HCl} 0.1$ \\
Eluent volume / mL & 0.2 \\
\hline
\end{tabular}

Interference of concomitant test

In addition to the optimization of the adsorption parameters, the evaluation of concomitant ions that could interfere in the determination of $\mathrm{Cr}$ was performed $\mathrm{Ca}^{2+}$, 
total $\mathrm{Fe}, \mathrm{Sr}^{2+}, \mathrm{Ba}^{2+}$, and $\mathrm{Mg}^{2+}$. A known amount of the interferent to be evaluated was added in the following proportions in relation to $\mathrm{Cr}, 1: 0.5 ; 1: 1$. After the procedure, the metal was detected by FAAS. The interference factor (FI) was determined, according to the equation 2 :

$\mathrm{FI}=\frac{\mathrm{A}^{\prime}}{\mathrm{A}}$

where $\mathrm{A}^{\prime}$ is the absorbance value relative to the chromium solution in the presence of the interferent and $\mathrm{A}$ is the absorbance of the chromium solution without interfering. The results obtained are presented in Table 2. A FI $=1$ indicates no interference, $\mathrm{FI}>1.1$ and $\mathrm{FI}<0.9$ indicate an increase or decrease in the analytical signal of the analytical signal by the presence of the interfering ion, respectively. ${ }^{51}$

Table 2. Interference factor of the liquid phase ions in the elution of $\mathrm{Cr}$

\begin{tabular}{lcc}
\hline \multirow{2}{*}{ Interfering } & \multicolumn{2}{c}{ Interference factor } \\
\cline { 2 - 3 } & $1: 0.5^{\mathrm{a}}$ & $1: 1^{\mathrm{a}}$ \\
\hline $\mathrm{Ca}^{2+}$ & 1.0 & 1.3 \\
$\mathrm{Total} \mathrm{Fe}$ & 1.3 & 1.4 \\
$\mathrm{Sr}^{2+}$ & 0.9 & 1.0 \\
$\mathrm{Ba}^{2+}$ & 0.8 & 0.9 \\
$\mathrm{Mg}^{2+}$ & 0.8 & 1.1 \\
\hline
\end{tabular}

${ }^{\mathrm{a} C h r o m i u m}$ :interfering.

According to the results presented in Table 2, some ions cause interference in the chromium absorbance signal. However, the proportion of analyte:interfering concentration was high in the tests carried out and they are expected to be present at lower concentrations in water samples. The analytical signal variations can be attributed both to the nature of the adsorbent and to specific phenomena of the FAAS technique. It is possible to occur competition of other cations by the adsorption sites; another possibility is based on the complexity of the steps existing in an atomization path, numerous analyte dissociation reactions. ${ }^{52}$ Studies ${ }^{52-55}$ indicate that problems related to chemical determinants of chromium can be solved by the addition of ethylenediamine tetraacetic acid (EDTA) as a masking agent for $\mathrm{Fe}^{2+}, \mathrm{Fe}^{3+}, \mathrm{Ca}^{2+}, \mathrm{Ba}^{2+}$ and $\mathrm{Mg}^{2+}$. Under these conditions, $\mathrm{Sr}^{2+}$ does not interfere. The use of a flame composed of nitrous oxide/acetylene can also contribute to reducing this problem..$^{53-55}$

\section{Figures of merit and analytical results}

Calibration curves for chromium have been established with blank and aqueous standard solutions in the concentration range between 0.01 and $2.0 \mathrm{mg} \mathrm{L}^{-1}$. The calibration equation was $\mathrm{Abs}=0.063 \mathrm{C}+0.0074$, where Abs is the absorbance signal and $\mathrm{C}$ is the concentration of chromium in $\mathrm{m} \mathrm{L}^{-1}$. Calibration curves in aqueous media and samples fortified with the standard of the analyte (Table 3) showed no significant difference in sensitivity at $95 \%$ confidence $(p>0.05)$. Under the optimized conditions, the linear regression coefficient, the limit of detection (LOD), and limit of quantification (LOQ) were $0.9951,6.00 \mu \mathrm{g} \mathrm{L}{ }^{-1}$, and $20.0 \mu \mathrm{g} \mathrm{L}^{-1}$, respectively, all obtained according to International Union of Pure and Applied Chemistry (IUPAC) guidelines. ${ }^{56}$ Relative standard deviation (RSD) for replicates was estimated at $1.3 \%$. The enhancement factor was calculated as the ratio between the slope of a calibration curve preconcentrated applying the DPX-SPE method and the curve without preconcentration. An enrichment factor of 12 was achieved by the preconcentration during the extraction procedure. These parameters are relevant to evaluate the performance of an analytical method for the determination of chemical species at sufficiently low concentrations with significant sensitivity improvement. The enrichment factor was already sufficient to obtain adequate LOD to monitor chromium concentrations according to the established standards.

The proposed method was applied to the determination of chromium in wastewater samples. To estimate the recovery efficiency of the method, the suggested procedure was applied in two samples, both samples were fortified with $1.0 \mathrm{mg} \mathrm{L}^{-1} \mathrm{Cr}$ solution. The results are shown in Table 3. Before analysis, the sample $\mathrm{pH}$ was adjusted at 2. Sample 1 presented $\mathrm{Cr}$ below the limit of detection and sample 2 presented chromium concentration within the limits provided by the legislation, showing the analytical viability of the method. Recoveries tests highlight the absence of matrix effect since the values obtained are within the acceptable range of 80 to $120 \% .^{56}$

Table 3. The determination of $\mathrm{Cr}$ in matrices water $(\mathrm{n}=3)$

\begin{tabular}{lcc}
\hline Sample & Found value $/\left(\mathrm{mg} \mathrm{mL}^{-1}\right)$ & Recovery / \% \\
\hline 1 & n.d. & - \\
1 (fortified) & $1.04 \pm 0.031$ & 104 \\
2 & $0.03 \pm 0.003$ & - \\
2 (fortified) & $1.17 \pm 0.030$ & 113 \\
\hline n.d.: not detected. & &
\end{tabular}

The recoveries obtained are comparable to values reported in the literature. The adequacy of the DPX-SPE method is verified in relation to similar works with other natural adsorbents, ${ }^{46,56}$ and involving other methods, ${ }^{46,56,57}$ such as cloud point extraction (CPE) ${ }^{58}$ and liquid phase derivatization by complexation with ammonium pyrrolidinedithiocarbamate (APDC) ${ }^{59}$ The silverskin 
Table 4. Comparison of recoveries obtained between similar chromium extraction methods

\begin{tabular}{|c|c|c|c|c|c|}
\hline Method & Detection technique & Sample & Solid phase & Recovery / \% & Reference \\
\hline$\overline{\text { SPE }}$ & FAAS & water & Moringa oleifera husks & 88 & 44 \\
\hline SPE & FAAS & $\begin{array}{l}\text { isotonic and energy } \\
\text { drinks samples }\end{array}$ & Luffa cylindrica fibers & 87.6 & 57 \\
\hline $\mathrm{CPE}$ & FAAS & water & - & 94.6 & 58 \\
\hline $\begin{array}{l}\text { Precolumn derivatization } \\
\text { with APDC }\end{array}$ & $\begin{array}{l}\text { HPLC-UV } \\
\text { photodiode array }\end{array}$ & $\begin{array}{l}\text { mineral mixtures and } \\
\text { feed samples }\end{array}$ & $\begin{array}{l}\text { polymer-based reversed-phase } \\
\text { column: phenomenex Kinetex C18 }\end{array}$ & $85-115$ & 59 \\
\hline SPE & ICP OES & water & $\begin{array}{l}\text { amino-propyl functionalized } \\
\text { mesoporous silica }\end{array}$ & $77.09-111.6$ & 60 \\
\hline
\end{tabular}

SPE: solid-phase extraction; CPE: cloud point extraction; APDC: ammonium pyrrolidinedithiocarbamate; FAAS: flame atomic absorption spectrometry; HPLC-UV: high-performance liquid chromatography-ultraviolet detection; ICP OES: inductively coupled plasma optical emission spectrometry.

coffee used as a new natural solid phase in this work was able to reach a more adequate recovery range compared to what was obtained with a synthetic material based on functionalized silica. ${ }^{60}$ Table 4 summarizes the comparison between recoveries reported by these works.

\section{Conclusions}

The alternative solid-phase extraction based on the DPX method developed in this study provided good sensitivity for the determination of chromium in wastewater samples. The coffee silverskin was efficient in $\mathrm{Cr}$ adsorption. LOD was achieved according to the CONAMA established standards. Extraction and preconcentration using DPX is a promising sustainable method, requiring low volumes of sample and diluted $\mathrm{HCl}$ solution for elution. The results indicate satisfactory conditions to promote the extraction and sufficient enrichment of chromium by DPX without the need for any chelating agent to favor the interaction with the solid phase. Control of the initial $\mathrm{pH}$ of the solution containing the ions of interest was sufficient for sample preparation. Regarding the applicability, the test of accuracy and tests of recovery in samples the values were satisfactory, showing that the method can be applied successfully in water samples and wastewater.

\section{Supplementary Information}

Supplementary information is available free of charge at http://jbcs.sbq.org.br as PDF file.

\section{Acknowledgments}

The authors are grateful for financial support from the Brazilian Federal Governamental and State funding agencies: Conselho Nacional de Desenvolvimento Científico e Tecnológico (CNPq), Fundação de Amparo à Pesquisa do Estado de Minas Gerais (FAPEMIG) and
Coordenação de Aperfeiçoamento de Pessoal de Nível Superior (CAPES).

\section{References}

1. Augustynowicz, J.; Grosicki, M.; Hanus, E.; Fajerska, M.; Lekka, M.; Koloczek, H.; Chemosphere 2010, 79, 1077.

2. Kumar, P.; Chauhan, M. S.; J. Environ. Chem. Eng. 2019, 7, 103218.

3. Walker, D. B.; Baumgartner, D. J.; Gerba, C. P.; Fitzsimmons, K. In Environmental and Pollution Science, $3^{\text {rd }}$ ed.; Brusseau, M. L.; Pepper, I. L.; Gerba, C. P., eds.; Academic Press: London, 2019, ch. 16, p. 261.

4. Kotaś, J.; Stasicka, Z.; Environ. Pollut. 2000, 107, 263.

5. Tchounwou, P. B.; Yedjou, C. G.; Patlolla, A. K.; Sutton, D. J. In Molecular, Clinical and Environmental Toxicology, vol. 3; Luch, A., ed.; Springer: Basel, 2012, p. 133.

6. Gomes, M. A. C.; Hauser-Davis, R. A.; Suzuki, M. S.; Vitória, A. P.; Ecotoxicol. Environ. Saf. 2017, 140, 55.

7. Conselho Nacional do Meio Ambiente (CONAMA); Resolução No. 430, Dispõe sobre As Condições e Padrões de Lançamento de Efluentes, Complementa e Altera a Resolução No. 357, de 17 de março de 2005; Diário Oficial da União (DOU), Brasília, No. 92 , de 16/05/2011, p. 89.

8. Saygi, K. O.; Tuzen, M.; Soylak, M.; Elci, L.; J. Hazard Mater. 2008, 153, 1009.

9. Karatepe, A.; Korkmaz, E.; Soylak, M.; Elci, L.; J. Hazard. Mater. 2010, 173, 433.

10. Béni, Á.; Dávid, N.; Kapitány, S.; Posta, J.; Microchem. J. 2019, 104077.

11. Shishov, A.; Terno, P.; Moskvin, L.; Bulatov, A.; Talanta 2020 , 206, 120209.

12. Tuze, M.; Elik, A.; Altunay, N.; J. Mol. Liq. 2021, 329, 115556.

13. Ali, J.; Tuzen, M.; Citak, D.; Uluozula, O. D.; Mendil, D.; Kazi, T. G.; Afridi, H. I.; J. Mol. Liq. 2019, 291, 111299.

14. Akhtar, A.; Kazi, T. G.; Afridi, H. I.; Khan, M.; Bilal, M.; Khan, N.; J. Ind. Eng. Chem. 2018, 59, 320.

15. Ghiasi, A.; Malekpour, A.; Microchem. J. 2020, 154, 104530. 
16. Shirani, M.; Salari, F.; Habibollahi, S.; Akbari, A.; Microchem. J. 2020, 152, 104340

17. Zhao, X.; Song, N.; Zhou, W.; Jia, Q.; Cent. Eur. J. Chem. 2012, $10,927$.

18. Yao, L.; Zhu, Y.; Xu, W.; Wang, H.; Wang, X.; Zhang, J.; Liu, H.; Lin, C.; J. Ind. Eng. Chem. 2019, 72, 189.

19. Bordin, D. C. M.; Alves, M. N. R.; de Campos, E. G.; de Martinis, B. S.; J. Sep. Sci. 2016, 39, 1168.

20. He, M.; Huang, L.; Zhao, B.; Chen, B.; Hu, B.; Anal. Chim. Acta 2017, 973, 1 .

21. Fernandes, V. C.; Domingues, V. F.; Mateus, N.; Matos, C. D.; J. Chromatogr. Sci. 2014, 52, 1339.

22. Corazza, G.; Merib, J.; do Carmo, S. N.; Mendes, L. D.; Carasek, E.; J. Braz. Chem. Soc. 2019, 30, 1211.

23. Corazza, G.; Merib, J.; Magosso, H. A.; Bittencourt, O. R.; Carasek, E.; J. Chromatogr. A 2017, 1513, 42.

24. Cadorim, H. R.; Schneider, M.; Hinz, J.; Luvizon, F.; Dias, A. N.; Carasek, E.; Welz, B.; Anal. Lett. 2019, 52, 2133.

25. Chaves, A. R.; Moura, B. H. F.; Caris, J. A.; Rabelo, D.; Queiroz, M. E. C.; J. Chromatogr. A 2015, 1399.

26. Alhogbi, B. G.; Sustainable Chem. Pharm. 2017, 6, 21.

27. Liu, F.; Hua, S.; Wang, C.; Qiu, M.; Jin, L.; Hu, B.; Chemosphere 2021, 279, 130539.

28. International Coffee Organization; https://www.ico.org/, accessed in December 2021.

29. Durán, C. A. A.; Tsukui, A.; Santos, F. K. F.; Martinez, S. T.; Bizzo, H. R.; Rezende, C. M.; Rev. Virtual Quim. 2017, 9, 107.

30. Janissen, B.; Huynh, T.; Resour., Conserv. Recycl. 2018, 128, 110.

31. Alves, V. N.; Neri, T. S.; Borges, S. S. O.; Carvalho, D. C.; Coelho, N. M. M.; Ecol. Eng. 2017, 106, 431.

32. Sanchez, D. A.; Anzola, C.; Rev. Colomb. Quim. 2012, 41, 2.

33. Souza, J. V. T. M.; Massocatto, C. L.; Diniz, K. M.; Tarley, C. R. T.; Caetano, J.; Dragunski, D. C.; Semina: Cienc. Exatas Tecnol. 2012, 33, 3 .

34. Nasiruddin Khan, M.; Sarwar, A.; Surf. Rev. Lett. 2007, 14, 461.

35. Pinto, M. A. L.; Queiroz, M. E. C.; Sci. Chromatogr. 2015, 7, 101.

36. Tomasin, G. S.; Silva, W. R.; Costa, B. E. S.; Coelho, N. M. M.; Microchem. J. 2021, 161, 105749

37. Araújo, C. S. T.; Melo, E. I.; Alves, V. N.; Coelho, N. M. M.; J. Braz. Chem. Soc. 2010, 21, 1727.

38. Bordin, D. C. M.; Alves, M. N. R.; Cabrices, O. G.; de Campos, E. G.; de Martinis, B. S.; J. Anal. Toxicol. 2014, 38, 31.

39. Yacoub, B. S.; Oudghiri, F.; Belkadi, M.; Barroso, R. R.; J. Therm. Anal. Calorim. 2019, 138, 1801.
40. Porto, D. S.; Forim, M. R.; Costa, E. S.; Fernandes, J. B.; da Silva, M. F. G. F.; J. Braz. Chem. Soc. 2021, 32, 29.

41. Vaz, S.; Lopes, W. T.; Martin-Neto, L.; Environ. Technol. Innovation 2015, 4, 260.

42. Mudunkotuwa, A. I.; Minshid, A. A.; Grassian, V. H.; Analyst 2014, 139, 870.

43. Santos, A. S.; Santos, T. S. M.; Lemos, V. A.; de Souza, A. O.; J. Braz. Chem. Soc. 2021, 32, 437.

44. Alves, V. N.; Coelho, N. M. M.; Microchem. J. 2013, 109, 16.

45. Kole, P. L.; Venkatesh, G.; Kotecha, J.; Sheshala, R.; Biomed. Chromatogr. 2011, 25, 199.

46. Mendes, M. F.; Freitas, S. S.; Estudos Interdisciplinares em Ciências Exatas e da Terra, $1^{\text {st }}$ ed.; Editora Blucher: São Paulo, 2016, p. 57.

47. Pagnanelli, F.; Beolchini, F.; Esposito, A.; Toro, L.; Vegliò, F.; Hydrometallurgy 2003, 71, 201.

48. Michalak, I.; Chojnacka, K.; Witek-Krowiak, A.; Appl. Biochem. Biotechnol. 2013, 170, 1389.

49. Mishra, A.; Tripathi, B. D.; Rai, A. K.; Ecotoxicol. Environ. Saf. 2016, 132, 420 .

50. Ho, Y. S.; Mckay, G.; Process Biochem. 1999, 34, 451.

51. Dedina, J.; Anal. Chem. 1982, 54, 2097.

52. Araújo, C. S. T.; Alves, V. N.; Rezende, H. C.; Coelho, N. M. M.; Microchem. J. 2010, 96, 82.

53. Ajlec, R.; Čop, M.; Štupar, J.; Analyst 1988, 4.

54. Bonnefoy, C.; Menudier, A.; Moesch, C.; Lachâtre, G.; Mermet, J. M.; Anal. Bioanal. Chem. 2005, 383, 167.

55. Zhang, H.; Liu, Q.; Wang, T.; Yun, Z.; Li, G.; Liu, J.; Jiang, G.; Anal. Chim. Acta 2013, 770, 140

56. Templeton, D. M.; Ariese, F.; Cornelis, R.; Danielsson, L.-G.; Muntau, H.; van Leeuwen, H. P.; Lobinski, R.; Pure Appl. Chem. 2000, 72, 1453.

57. de Souza Neto, J. A.; Oliveira, J. A. N.; Siqueira, L. M. C.; Alves, V. N.; J. Chem. 2019, 2019, 1679419.

58. Zhang, L.; Li, X.; Wang, X.; Wang, W.; Wang, X.; Han, H.; Anal. Methods 2014, 6, 5578.

59. Umesh, B.; Rajendran, R. M.; Manoharan, M. T.; Poult. Sci. 2015, 94, 2805

60. Idris, S. A.; Alotaibi, K.; Peshkur, T. A.; Anderson, P.; Gibson, L. T.; J. Colloid Interface Sci. 2012, 386, 344.

Submitted: June 21, 2021

Published online: December 17, 2021 